\title{
Metodologias ativas de ensino aprendizagem na graduação em Odontologia e a contribuição da monitoria - relato de experiência
}

Marília Araújo Reul*; Elisa Diniz de Lima*; Késsia do Nascimento Irineu*; Rilva Suely de Castro Cardoso Lucas**; Edja Maria Melo de Brito Costa**; Renata Cardoso Rocha Madruga**

* Aluna de graduação em Odontologia, UEPB

** Professora do Departamento de Odontologia, UEPB

\section{RESUMO}

$\mathrm{Na}$ área da saúde estão sendo adotadas formas diferenciadas de ensino-aprendizagem e de organização curricular na perspectiva de integrar a teoria com a prática e o ensino com o serviço, além de desenvolver capacidade reflexiva acerca de problemas reais, assim como, o planejamento de ações originais e criativas capazes de modificar a realidade social. No Componente Curricular Estágio Supervisionado II, do curso de Odontologia da Universidade Estadual da Paraíba, os docentes vêm utilizando as Metodologias Ativas, a exemplo da problematização, que consiste na utilização de disparadores do processo de ensino-aprendizagem para estabelecer o debate. Como forma de avaliação da aprendizagem, o portfólio crítico reflexivo é utilizado com registros fotográficos, impressões positivas e negativas da vivência durante o Estágio Supervisionado. Além destas, a internet é utilizada como tecnologia de informação e comunicação, em que o componente possui um grupo em rede social, o facebook, que é utilizado para comunicação entre os docentes, discentes e monitores para discussão de artigos, documentários e temas relacionados às aulas. A monitoria do Estágio Supervisionado vem contribuindo para a criação de um perfil discente crítico reflexivo e estimulando a vocação dos monitores para a docência. Sendo assim, o uso de metodologias ativas de ensinoaprendizagem tem despertado o interesse do aluno para o pensar, questionar, aprender a aprender e assumir seu papel como futuro transformador da realidade social, o que tem contribuído sobremaneira na inovação das práticas docentes e estimulado, na monitoria, o desenvolvimento das competências do perfil docente requerido na atualidade.

DESCRITORES: Aprendizagem. Educação Superior. Currículo. Docentes.

\section{INTRODUÇÃO}

$\mathrm{Na}$ área da saúde, têm-se apontado caminhos inovadores para a capacitação e formação dos profissionais. Adotam-se, então, formas diferenciadas de ensinoaprendizagem e de organização curricular na perspectiva de interligar a teoria com a prática e o ensino com o serviço, além de desenvolver a capacidade reflexiva acerca de problemas reais e a formulação de ações originais e criativas capazes de modificar a realidade 
social $^{1}$.

É preciso modernizar a educação de modo que acompanhe as transformações ocorridas no mundo. Os métodos e os recursos do processo de ensino e aprendizagem são variados $^{2}$. Como as teorias precisam ser renovadas ou confirmadas permanentemente, para conduzir esta dinâmica, é necessário realizar uma contínua avaliação, a fim de acompanhar as descobertas científicas ${ }^{3}$.

Dentre as metodologias ativas destacam-se a problematização, a aprendizagem baseada em problemas / problem based learning (ABP/ $\mathrm{PBL}), \mathrm{o}$ portfólio crítico reflexivo (PCR) e as tecnologias de informação e comunicação (TICs), as quais vêm ganhando destaque. A problematização e a ABP, embora distintas, apresentam semelhanças e ambas se propõem a romper com os métodos tradicionais de ensino-aprendizagem ${ }^{4}$.

A problematização se opõe ao ensino tradicional por não operar na lógica do repasse de informações ou conhecimentos, mas em movimentos que concebem possibilidades para a sua construção ou produção. Ademais, tem por finalidade provocar o aparecimento de outras formas de ensinar e de aprender, nas quais os estudantes e professores são coparticipantes do processo ${ }^{5}$.

A ABP propicia aos discentes o desenvolvimento de perfil crítico reflexivo, pois os estudantes devem procurar o conhecimento por si mesmos ao se depararem com uma situação problema ou um caso clínico ${ }^{3}$.

O PCR representa uma ferramenta útil não somente para avaliação de desempenho. É, sobretudo, uma estratégia para estimular a aprendizagem baseada nas competências na perspectiva de "se aprende o que se faz e o que se faz se aprende" 6 .

As TICs são importantes aliadas no processo de ensino - aprendizagem, pois atingiram para além da vida sociocultural das pessoas, chegando, da mesma forma, nas escolas e universidades, impondo aos alunos e professores, novos paradigmas no cenário da educação. Deve-se ter clareza de que os processos pedagógicos sejam tratados de forma associativa e não separadamente, fazendo com que o domínio das técnicas aconteça por necessidade e exigência, constituindo um verdadeiro pacto de aprendizagem ascendente na sua complexidade ${ }^{2}$.

Diante destas mudanças pedagógicas, não se pode falar em aprendizagem sem ressaltar o papel do docente frente ao uso destas metodologias ativas de forma apropriada e contextualizada, mantendo-se em constante atualização para desempenhar sua função na construção de um ensino de qualidade ${ }^{7}$.

Além disso, com o uso das metodologias ativas, o componente curricular vem tentando desenvolver o perfil discente exigido pelas diretrizes curriculares para o curso de Odontologia e estimulando nos monitores a vocação para docência, tendo em vista que promove a cooperação entre os corpos docente e discente, em benefício da qualidade do ensino, ministrado pela Instituição.

Face ao exposto, pretende-se com este artigo delinear as metodologias ativas utilizadas durante o componente curricular Estágio Supervisionado II, do curso de Odontologia da Universidade Estadual da Paraíba, centrada no estudante, cabendo ao professor o papel de facilitador no processo de construção do conhecimento, enfatizando os novos desafios existentes para um aluno que visa uma carreira docente.

\section{RELATO DE EXPERIÊNCIA}

O componente curricular Estágio 
Supervisionado II busca, por intermédio de metodologias ativas, a exemplo da problematização e do PCR, desenvolver nos discentes competências que possam convergir com as necessidades do perfil profissional esperado para atuar com qualidade e resolutividade no Sistema Único de Saúde (SUS).

$\mathrm{Na}$ problematização, os docentes têm utilizado disparadores do processo ensinoaprendizagem, a exemplo de narrativas de uma situação problema (SP), artigos científicos que abordem o tema da aula, além de outras ferramentas como filmes, curtasmetragens e documentários que, de forma lúdica, têm contribuído para suscitar o debate e identificar questões de aprendizagem a serem aprofundadas.

A ABP consiste em uma SP identificada a ser discutida, servindo para potencializar o debate e apontar estratégias a fim de responder as questões inerentes à mesma, de forma que todos reflitam sob dada circunstância e aprendam juntos a apontar saídas para tal. Como forma de responder ao problema, estimula-se que os discentes façam buscas bibliográficas, leiam textos, busquem artigos científicos, capítulos de livros e, a partir do aprofundamento teórico, desenvolvam respostas e socializem em uma roda de diálogo o percurso de sua aprendizagem.

O componente curricular disponibiliza orientações para a elaboração do PCR, que consiste na produção escrita da vivência no Estágio Supervisionado II nos diversos cenários de prática em Unidades Básicas de Saúde da Família (UBSFs) com registros escritos e fotográficos de todas as impressões, opiniões, dúvidas, aprofundamento teórico da equipe, de forma a se ter um produto do percurso histórico de todos os fatos e situações vivenciadas no estágio, para além de um relato (figura 1), também utilizado como forma de avaliação do processo ensino-aprendizagem.

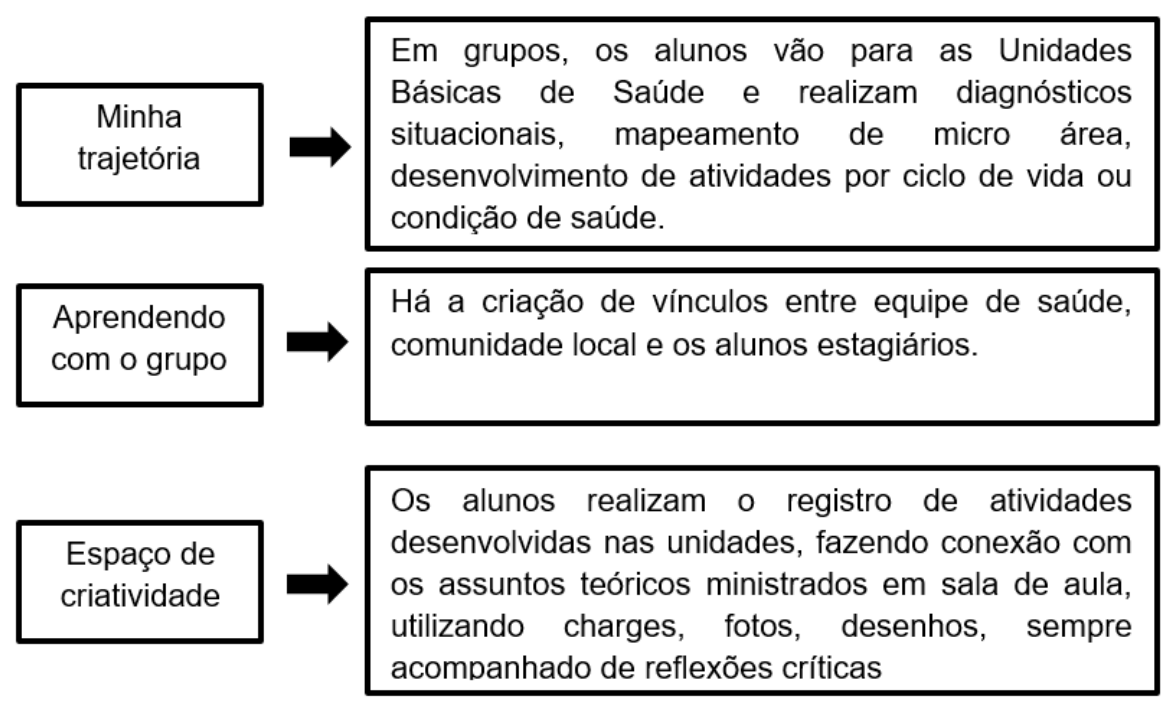

Figura 1. Fluxograma para a estruturação dos portfólios

Além dos recursos citados sibilitando aos acadêmicos o acesso a diversos anteriormente, a internet tem sido uma outra artigos, links, além de facilitar a comunicação ferramenta utilizada como TIC, pos- entre os docentes, discentes e monitores do 
componente curricular por meio de e-mails coletivos e "Grupo da Monitoria" criado em rede social (Facebook) em que participam ativamente das discussões e socialização das referências (fontes de pesquisa).

$\mathrm{Na}$ intenção de otimizar o tempo, o componente curricular é contemplado com monitores que auxiliam os docentes e os discentes em suas atribuições intra e extraclasse. Neste sentido, os monitores fazem uso de assessoria presencial e não presencial, sendo estas o atendimento a alunos propriamente dito e o atendimento utilizando ferramentas ofertadas pelas TICs.

Nas atividades realizadas em sala de aula, parte-se do pressuposto de que o estudante é sujeito ativo do processo ensinoaprendizagem. Em um primeiro momento, os alunos são divididos em grupos e apresentam seminários sobre as Conferências de Promoção à Saúde realizadas até então, além de uma resenha crítica sobre o livro "Saúde para todos, já!" da autora Lana Bleicher. Após a entrega da atividade, estudam temas como: Atenção Primária a Saúde e Estratégia de Saúde da Família, Escolas Promotoras de Saúde, além de outros, tais como Ambientes Saudáveis, Cidades Saudáveis. Ao final, constroem um plano de ação que será posteriormente aplicado no estágio de vivência em uma UBSF.

No semestre seguinte, as professoras do componente curricular acessam a Secretaria de Saúde do município de Campina Grande (PB), buscando apoio e consentimento para a realização do estágio. Posteriormente, acontece uma reunião entre as professoras, a coordenação de Saúde Bucal e Apoiadores dos Distritos Sanitários para a seleção das Unidades de Saúde e a efetivação dos estágios.

Após a escolha das Unidades Básicas de Saúde (UBS), os cirurgiões dentistas (preceptores) das UBSs são convidados a irem à Universidade para que haja um contato prévio entre eles e os alunos. É neste momento que há uma sensibilização e os futuros estagiários apresentam seus planos de ação, realizando uma troca de experiências e expectativas de como será o desenvolvimento do estágio.

Os alunos dividem-se em duplas ou trios e realizam o estágio nas UBSFs, entrando em contato com os profissionais e comunidade durante dez semanas em que realizam atividades socioeducativas, explorando todo o conhecimento trabalhado previamente em sala de aula.

Ao final de dez encontros nestes cenários de prática, os discentes apresentam em seminários sua vivência no Estágio Supervisionado II, enfocando o serviço e sua articulação entre o preceptor, os estagiários, os demais profissionais da unidade e a comunidade. Neste contexto, expõem as atribuições dos profissionais e estagiários, dificuldades enfrentadas, conquistas na realização das atividades, experiências positivas e negativas, e necessidade de adequação das propostas à realidade encontrada na comunidade no período de aplicação do plano de ação.

De forma semelhante à apresentação dos seminários, os discentes também preparam um PCR deste período de vivências, registrando suas impressões, dificuldades, conquistas e o trabalho realizado na comunidade e na UBSF. Estes são entregues aos docentes, compondo uma das avaliações formativas da disciplina. Outro segmento de avaliação (avaliação somativa) se dá por intermédio de instrumentos em que os preceptores avaliam os alunos. Estes, por sua vez, avaliam a si próprios e as professoras do componente curricular, ponderam suas avaliações aos preceptores e aos alunos.

Ao final das apresentações são discutidos os pontos abordados e se estimula posicionamento crítico reflexivo quanto à realidade vivenciada por cada aluno. Posteriormente são escolhidos dois discentes que serão responsáveis por sintetizar estas vivências e apresentá-las na forma de seminário aos preceptores e técnicos da Secretaria Municipal de Saúde, fornecendo para o serviço e gestão feedback para melhor planejamento e desenvolvimento das ações futuras.

\section{CONSIDERAÇÕES FINAIS}

A necessidade de rompimento com o 
modelo de formação tradicional (clássico ou cartesiano) que vem há décadas sendo utilizado para a formação de profissionais da saúde, explica a amplitude e inovação que ganharam as discussões relacionadas ao emprego das metodologias ativas de ensinoaprendizagem nesse campo ${ }^{8}$.

$\mathrm{O}$ modelo tradicional desconsidera as necessidades do SUS e forma profissionais despreparados para lidar com a sua realidade, sem adquirir um perfil crítico-reflexivo e sem capacidades de desenvolver trabalho em grupo ${ }^{9}$.

Para Freitas ${ }^{3}$, os métodos de ensino ultrapassados podem não privilegiar a inteligência e a criatividade dos jovens, assim como, a eficiência da aprendizagem nas Universidades e na capacitação dos profissionais. Então, é preciso modernizar a educação para acompanhar as transformações ocorridas no mundo. Há uma imperiosa necessidade de mudanças no ensino para acompanhar as transformações na prática científica e na realidade contemporânea.

O emprego das metodologias ativas na Odontologia pode ser influenciado pelo tipo da população-alvo, pela disponibilidade dos alunos para a aprendizagem e pela habilidade do professor em escolher uma metodologia apropriada ao que pretenda ensinar ${ }^{10}$.

O uso da problematização como uma metodologia de ensino está indicado quando os temas a serem trabalhados estejam relacionados com a vida em sociedade, apresentando os problemas e estimulando os discentes a aprender a resolvê-los.

Ao contrário das práticas educativas individuais, a problematização torna-se uma metodologia de ensino que concebe a educação como um exercício social. E na medida em que vivemos em um mundo de rápidas mudanças, o essencial não são apenas os conhecimentos e as ideias, mas, sobretudo, o aumento da capacidade do estudante para detectar os problemas reais e buscar soluções criativas e originais.

As metodologias ativas são um desafio para os educadores, visto que para sua utilização não é necessário apenas conhecer os modos de operacionalização, mas também, os princípios da pedagogia crítica9 ${ }^{9}$

Não se pode falar em aprendizagem sem falar no professor. O contexto social na atualidade impõe a prática educativa um número de demandas muito grande, levando ao educador do século XXI a repensar a sua atuação em sala de aula, trazendo em consideração os enormes desafios profissionais que enfrenta a fim de atingir as expectativas do contexto atual ${ }^{12}$.

A pedagogia crítica afirma que o docente terá o papel de mediador no processo de ensino-aprendizagem, tendo função de conduzir os discentes a observação da realidade e apreensão do conteúdo que dela extraem a partir dos temas apresentados ${ }^{9}$. O docente não será o único determinante para o sucesso de tal metodologia, nesse processo de educação os discentes devem se tornar autônomos e responsáveis pela aprendizagem, portanto o processo educativo tem aspectos de corresponsabilidade entre docente e discente ${ }^{8-}$ 9,11

Atualmente, é necessário que o professor ultrapasse a fundamentação técnica e fragmentada, para que possa agir em situações novas e problemáticas. O processo de atualização e formação docente se prolonga por todo seu trajeto profissional, mediante uma relação dialética na qual é defendida por Freire ${ }^{13}$ quando se coloca: "Quem ensina aprende ao ensinar quem aprende ensina ao aprender".

Nessa relação o monitor atua como elo entre o docente e os discentes, corroborando de forma favorável para um maior aproveitamento do tempo, do conteúdo e do conhecimento gradualmente construído. O mesmo também estará se relacionando de forma mais íntima com a vivência de um docente e desenvolvendo competências que posteriormente lhe serão indispensáveis para ser um profissional mais útil à sociedade.

Através da experiência das atividades que competem ao monitor, tais como participação nas discussões, atualização das aulas, suporte em dúvidas presenciais e online (e-mail e grupo em rede social), aprofundamento teórico dos temas, busca de referências para fundamentação de resumos, 
apresentação de trabalho em eventos, etc. Todas estas atividades têm proporcionado aos monitores uma maior integração com a docência e com esta metodologia de ensinoaprendizagem.

A monitoria tem despertado nos monitores o interesse pela docência. $O$ contato com as metodologias ativas de ensinoaprendizagem tem proporcionado uma visão mais crítica da realidade da sala de aula e potencializado o desejo no monitor de se tornar um profissional que busque desenvolver as competências de questionar, construir, discutir, trabalhar em grupo e constantemente está se reinventando, assim como foi observado no período desta experiência.

As metodologias ativas de ensinoaprendizagem são um desafio para o docente, assim como para o discente e as instituições, por não favorecerem o seu desenvolvimento por intermédio de uma grade curricular tradicional em que há a fragmentação do saber e a dicotomia entre os aspectos teóricos e práticos. Este mesmo modelo também persiste em decorrência de haver uma ampla geração de docentes que corroboram com esse modelo e o aplicam e o estimulam em sala de aula. Estas metodologias devem ser instigadas dentro e fora da sala de aula e discutidas nas coordenações dos cursos, para que possa haver uma maior aceitação por parte dos demais docentes da instituição, entendendo que nem todos os componentes curriculares podem fazer uso das mesmas ferramentas. No entanto, sempre há uma forma de adequação ao conteúdo ao qual se pretende trabalhar. É indispensável que o profissional (docente ou não), esteja continuamente se reinventando para que assim possa haver um resultado mais efetivo de suas ações e pretensões.

Em conclusão, a experiência na monitoria de Estágio Supervisionado permitiu que os monitores tivessem um olhar mais crítico-reflexivo da realidade, contribuindo de forma positiva para a propagação do desenvolvimento dessa metodologia e de uma visão crítica sobre as suas atribuições, assim como, o despertar para a docência.

\section{ABSTRACT \\ Active teaching-learning methods for graduation in Dentistry and contribution of monitoring - an experience report}

In the health field, different ways of teachinglearning and curricular organization are being adopted in the perspective to integrating theory with practice and teaching with the service, and to develop the reflective capacity about real problems, as well as planning creative and original actions that are capable to change the social reality. In the curricular component Supervised Internship II, at the State University of Paraíba - Dentistry Course, the teachers have been using the active methodologies, such as the questioning, which is the use of triggers of the teachinglearning process to establish the debate. As a way of assessing learning, a reflective critical portfolio is used with photographic records, with the positive and negative impressions of the experience during the supervised internship. In addition, the internet is used as a technology of information and communication, in which the component has a group on social network, Facebook, which is used for communication between teachers, students and monitors for mailing articles, documentaries and issues related to classes. The monitoring of the Supervised Internship has contributed to the creation of a criticalreflective student profile and stimulated the monitors' skills for teaching. Thus, the use of active teaching-learning methodologies has aroused the interest of the student to think, to question, to learn and to take their role as future transformer of the social reality, which has contributed greatly to the teaching practice innovation and encouraged, in monitoring, the development of the skills of the teaching profile required nowadays.

Descriptors: Learning. Education, Higher. Curriculum. Faculty

\section{REFERÊNCIAS}

1. Marin MJS, Lima EFG, Paviotti AB, Matsuyama DT, Silva LKD, Gonzalez K, 
et al. Aspectos das fortalezas e fragilidades no uso das metodologias ativas de aprendizagem. Rev Bras Educ Méd. 2010, 34 (1):13-20.

2. Santos A. Tecnologias de informação e comunicação: limites e possibilidades no ensino superior. Anuário da produção acadêmica docente. 2011, 5(12):129-50.

3. Freitas VP, Carvalho RB, Gomes MJ, Figueiredo MC, Faustino-Silva DD. Mudança no processo ensinoaprendizagem nos cursos de graduação em odontologia com utilização de metodologias ativas de ensino e aprendizagem. RFO. 2009, 14(2):163-67.

4. Smolka MLRM, Gomes AP, SiqueiraBatista R. Autonomia no Contexto Pedagógico: Percepção de Estudantes de Medicina acerca da Aprendizagem Baseada em Problemas. Rev Bras Educ Méd. 2014, 38(1):5-14.

5. Gomes MPC, Ribeiro VMB, Monteiro DM, Leher EMT, Louzada RCR. O uso de metodologias ativas no ensino de graduação nas ciências sociais e da saúde Avaliação dos estudantes. Ciênc Educ. 2010, 16(1):181-98.

6. Cotta RMM, Costa GD, Mendonça ET. Portfólio reflexivo: uma proposta de ensino e aprendizagem orientada por competências. Ciênc Saúde Coletiva. 2013, 18(6):1847-56.

7. Leite C, Ramos K. Formação para a docência universitária: uma reflexão sobre o desafio de humanizar a cultura científica. Revista Portuguesa de Educação. 2012, 25(1):7-27.

8. Sobral FR, Campos CJG. The use of active methodology in nursing care and teaching in national productions: an integrative review. Rev Esc Enferm USP. 2012, 46(1):202-11.

9. Prado ML, Velho MB, Espíndola DS, Sobrinho SH, Backes VMS. Arco de
Charles Maguerez: refletindo estratégias de metodologia ativa na formação de profissionais de saúde. Esc Anna Nery. 2012, 16(1):172-77.

10. Silva KASR. A docência e seus desafios: um olhar crítico acerca da comercialização da educação. Rev Ciênc Hum. 2013, 6(1):107-19.

11. Cotta RMM, Reis RS, Campos AAO, Gomes AP, Antonio VE, Siqueira-Batista R. Debates atuais em humanização e saúde: quem somos nós?. Ciênc Saúde Coletiva. 2013, 18(1):171-79.

12. Finkler M, Caetano JC, Ramos FRS. A dimensão ética da formação profissional em saúde: estudo de caso com cursos de graduação em odontologia. Ciênc Saúde Coletiva. 2011, 16(11):4481-92.

13. Freire P. Pedagogia da Autonomia Saberes Necessários à Prática Educativa.43th ed. São Paulo: Paz e Terra, 2011.

Correspondência para:

Renata Cardoso Rocha Madruga e-mail: renata.rocha@oi.com.br R. José Aranha, n 509 - Nova Brasília 58406-885 Campina Grande/PB 